\title{
Ph-Metric Study of Binary and Ternary Complexes of Innertransition Metals With Carboxylic Acids and Amino Acids
}

\author{
Suresh D. Dhage ${ }^{1,}$ Mahesh B. Swami ${ }^{2}$ \\ ${ }^{l}$ Department of Chemistry, SSJES, Arts, Commerce \& Science College, Gangakhed-431514 Dist. \\ Parbhani.(M.S.)India \\ ${ }^{2}$ Department of Chemistry, B. S. College, Basmathnagar,- 413515 Dist. Hingoli.(M.S.)India
}

\begin{abstract}
The present work deals with the study of proton - ligands and metal- ligands Constant of Binary and ternary complexes. Where $M=$ Innertranition metals, $L=$ Primary ligands (malic acid, , maleic acid and Malonic acid) and secondary ligands $B=$ Glycine have been studied Potentiometrically in biologically relevant conditions. At ionic strength $\mu=0.1 \mathrm{M} \mathrm{NaClO}$. All the ligands forns 1:1:1 ternary complexes, the relative stability of ternary complexes expressed in terms of statistical parameter $\Delta \log k$ and $-\Delta \log k$ values suggest that the formation of ternary complexes are favorable and variation of $\Delta \log k$ has been explained in terms of metal-ligand-n interaction, size of chelate ring, and steric factor.
\end{abstract}

Key words: $p H$-metric study, formation constants, binary, ternary complexes.

\section{Introduction}

The lanthanides are given unique position in the periodic table due to their various chemical and physical characerstics ${ }^{1}$. Therefore the study of coordination chemistry of lanthanides has attracted the attention of several workers during last two to three decades. There fore it is considerable interest in the study of binary and ternary complexes of lanthanides by $\mathrm{pH}$ - metric methods $\mathrm{s}^{2-5}$.

The study of Kinetic parameter and formation constants of ( Mn- antibiotics cefoperazone) complexes Vis-à-vis Kinetics of electrode reaction have been investigated by Farid Khan \& Rakhi Agrawal ${ }^{6}$

The study of formation constants of metal-methionine and metal-methionine NTA (Nitrilotriacetic acid) (binary and mixed) Complexes have been investigated by Praveen P.Singh etal. ${ }^{7}$

Siddiqui et al ${ }^{8-9}$ studied the complexes of lanthanide ion with drug molecule like barbituric acid derivatives and suggested the ionic character of metal ligand bonds in the complexes. Nahendram et al ${ }^{10}$. Also suggest that the ionic nature of metal ligand bond in complexes of lanthanides with 2-hydroxy methyl benzimidazole, among the numerous selective and specific complexing agents, the biologically active ligands like drug molecules have special importance in the formation of lanthanidecomplexes.

A search through the literature has revealed that there is no systematic study on stability constant of binary and ternary complexes of these metal ions with ligands have studied using Irving Rossotti pH- metric titration techniques in aqueous medium in the present work.

\section{Experimental}

All the ligands was obtained from $\mathrm{AR}$ grade. $\mathrm{NaClO}_{4}$ was used from fluka chemical. $\mathrm{NaOH}$ was standardized by standard KHP from AR grade ${ }^{12}$. All other Solution was prepared in doubly distilled water. The pH-metry measurement work carried out by using ELICO digital model LI - $120 \mathrm{pH}$-meter with glass calomel electrode with an accuracy of \pm 0.01 of $\mathrm{pH}$ unit at $25 \pm 0.1^{\circ} \mathrm{C}$ was standardized against $0.05 \mathrm{M} \mathrm{KHP}(4 \mathrm{pH}) 0.01 \mathrm{M}$ borax solution $(9.18 \mathrm{pH})$ for the determination of proton-ligand stability constant of the secondary ligands and metal-ligands stability constants of the binary and ternary complexes the following sets of solution were prepared and titrated against stand. Alkali solution.

Binary System

a] $2 \times 10^{-1} \mathrm{M} \mathrm{HClO}_{4}$

b] a $+1 \times 10^{-2} \mathrm{M}$ primary ligands.

c] $\mathrm{a}+\mathrm{b}+1 \times 10^{-2} \mathrm{M}$ metal ions.

d] $\mathrm{a}+1 \times 10^{-2} \mathrm{M}$ secondary ligands.

e] $\mathrm{d}+1 \times 10^{-2} \mathrm{M}$ metal ions.

4] $\mathrm{b}+1 \times 10^{-2} \mathrm{M}$ secondary ligands $+1 \times 10^{-2} \mathrm{M}$ metal ions.

The ionic strength of above solution was mentioned at $0.1 \mathrm{M}$ constant by adding of $(1 \mathrm{M}) \mathrm{NaClO}_{4}$.and total volume of solution was made $50 \mathrm{ml}$. 


\section{Results And Discussion}

Stability constants of these ligands are determined by Irving- Rossotti techniques ${ }^{11}$ at constant temperature $25 \pm 0.1^{0} \mathrm{C}$ in $60 \%$ ethanol-water medium.

Proton ligand and metal ligand stability constant of primary ligands with lanthanides are calculated by Irving-Rossotti titration method and represented in table-1. Primary ligand forms 1:1 and 1:2 complexes with lanthanides in the $\mathrm{pH}$ range. Stability constant of bivalent metal complexes derived from similar type of ligands. The deviations of (acid +ligand) curve from (acid +ligand +metal ion) curve along volume axis indicate the formation of complex species shown in fig.1. and it lies in the $\mathrm{pH}-$ region, where hydrolysis is not expected. Metal ligand stability constant of primary and secondary ligand are given in table -2 .

Table I: PROTON - LIGAND STABILITY CONSTANTS. Temperature $=25 \pm 0.1^{\circ} \mathrm{C} .\left(\mu=0.1 \mathrm{M} \mathrm{NaClO}_{4}\right)$

\begin{tabular}{lll}
\hline Ligand & $\log \mathrm{K}_{1}^{\mathrm{H}}$ & $\log \mathrm{K}_{2}^{\mathrm{H}}$ \\
\hline Malonic acid & 9.519 & 11.360 \\
Malic acid & 8.828 & 11.873 \\
Maleic acid & 8.550 & 11.934 \\
\hline
\end{tabular}

The stability constant of bivalent metal complexes derived from similar type of ligands generally follow Irving-Rossotti techniques and present complexes follow the order of stability as.

$$
\mathrm{L}_{1}=\mathrm{L}_{3}=
$$

Dy>

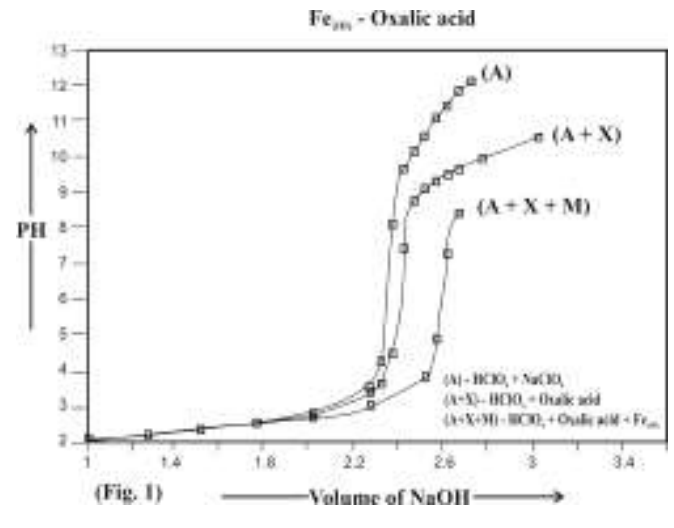

$\mathrm{Tb}>\mathrm{Eu}>\mathrm{Sm}>\mathrm{Nd}>\mathrm{Gd}>\mathrm{Pr}>\mathrm{Ce}>\mathrm{La}$.

$\mathrm{L}_{2}=\mathrm{Dy}>\mathrm{Tb}>\mathrm{Eu}>\mathrm{Sm}>\mathrm{Gd}>\mathrm{Nd}>\mathrm{Pr}>\mathrm{Ce}>\mathrm{La}$.

TABLE - 2: METAL - LIGAND STABILITY CONSTANTS

\begin{tabular}{|c|c|c|c|c|c|c|}
\hline \multirow{2}{*}{ Metal } & \multirow{2}{*}{$\begin{array}{l}\text { Stability } \\
\text { Constant }\end{array}$} & \multicolumn{5}{|l|}{ Ligands } \\
\hline & & Glycine & Alanine & Malic acid & Maleic acid & Malonic acid \\
\hline $\mathrm{La}_{\text {(III) }}$ & $\log \mathrm{K}_{1}^{\mathrm{M}}$ & 5.32 & 5.30 & 5.47 & 6.30 & 5.34 \\
\hline $\mathrm{Ce}_{(\mathrm{III})}$ & $\log \mathrm{K}_{1}^{\mathrm{M}}$ & 5.40 & 5.42 & 5.76 & 6.61 & 5.72 \\
\hline $\operatorname{Pr}_{\text {(III) }}$ & $\log \mathrm{K}_{1}^{\mathrm{M}}$ & 5.54 & 5.56 & 6.18 & 6.62 & 5.92 \\
\hline $\mathrm{Nd}_{(\mathrm{III})}$ & $\log \mathrm{K}_{1}^{\mathrm{M}}$ & 5.64 & 5.66 & 6.75 & 6.78 & 6.01 \\
\hline $\mathrm{Sm}_{\text {(III) }}$ & $\log \mathrm{K}_{1}^{\mathrm{M}}$ & 5.75 & 5.76 & 6.77 & 6.84 & 6.12 \\
\hline $\mathrm{Eu}_{(\mathrm{III})}$ & $\log \mathrm{K}_{1}^{\mathrm{M}}$ & 5.80 & 5.82 & 6.82 & 6.98 & 6.10 \\
\hline $\mathrm{Gd}_{\text {(III) }}$ & $\log \mathrm{K}_{1}^{\mathrm{M}}$ & 5.72 & 5.70 & 6.72 & 6.80 & 5.94 \\
\hline $\mathrm{Tb}_{\text {(III) }}$ & $\log \mathrm{K}_{1}^{\mathrm{M}}$ & 5.92 & 5.93 & 6.92 & 7.10 & 6.26 \\
\hline $\mathrm{Dy}_{(\text {III) }}$ & $\log \mathrm{K}_{1}^{\mathrm{M}}$ & 6.10 & 6.08 & 7.20 & 7.22 & 6.32 \\
\hline
\end{tabular}

\section{Formation of Ternary Complexes:-}

The formation equilibria of mixed ligand complexes with the ligands and lanthanides are 1:1:1ternary complexes and these are formed by simultaneous equilibrium. The preferential formation of ternary complexes over binary complexes has been discussed in terms of equilibrium constants and on the basis of speciation curves and percentage concentration species $\mathrm{F}_{\mathrm{M}}, \mathrm{F}_{\mathrm{L}}$ and $\mathrm{F}_{\mathrm{B} .}$ and stability constant of ternary complexes are calculated by using SCOG computer program and values are given in table -3 .

The relative order of stability of ternary complexes in terms of the metal ions as found in this work are

$\mathrm{Dy}>\mathrm{Tb}>\mathrm{Gd}>\mathrm{Eu}>\mathrm{Sm}>\mathrm{Nd}>\mathrm{Pr}>\mathrm{Ce}>\mathrm{La}$.

Which may be attributed to decreasing size and increasing charge / radius ratio of metal ions.

Formation constant of the complexes were calculated by using the SCOGS computer programe ${ }^{12}$. Estimate of some of the binary constant were obtained by the method of Irving and Rossotti's. overall constant $\mathrm{B}_{02}, \mathrm{~B}_{20}, \mathrm{~B}_{11}$ 
were obtained as computer out puts, from which the other constants were calculated using the appropriate reactions.

TABLE - 3: STABILITY CONSTANTS OF MIXED LIGAND COMPLEXES:

\begin{tabular}{|c|c|c|c|}
\hline Metal ion & Mixed ligand system & $\log K_{M X Y}$ & $\Delta \log K$ \\
\hline $\mathrm{La}_{\text {(III) }}$ & $\begin{array}{l}\text { Glycine - Malic acid } \\
\text { Glycine - Maleic acid } \\
\text { Glycine - Malonic acid }\end{array}$ & \begin{tabular}{|l|}
9.226 \\
13.942 \\
13.017 \\
\end{tabular} & $\begin{array}{l}1.564 \\
-2.322 \\
-2.357 \\
\end{array}$ \\
\hline $\mathrm{Ce}_{(\mathrm{III})}$ & $\begin{array}{l}\text { Glycine - Malic acid } \\
\text { Glycine - Maleic acid } \\
\text { Glycine - Malonic acid }\end{array}$ & $\begin{array}{l}9.463 \\
14.181 \\
15.585\end{array}$ & $\begin{array}{l}1.697 \\
-2.171 \\
-2.690\end{array}$ \\
\hline $\operatorname{Pr}_{(\text {III })}$ & $\begin{array}{l}\text { Glycine - Malic acid } \\
\text { Glycine - Maleic acid } \\
\text { Glycine - Malonic acid }\end{array}$ & \begin{tabular}{|l|}
10.030 \\
14.245 \\
14.155 \\
\end{tabular} & \begin{tabular}{|l|}
1.690 \\
-2.085 \\
-2.695 \\
\end{tabular} \\
\hline $\mathrm{Nd}_{\text {(III) }}$ & $\begin{array}{l}\text { Glycine - Malic acid } \\
\text { Glycine - Maleic acid } \\
\text { Glycine - Malonic acid }\end{array}$ & $\begin{array}{l}09.084 \\
15.175 \\
14.816\end{array}$ & $\begin{array}{l}3.306 \\
-2.755 \\
-2.505\end{array}$ \\
\hline $\mathrm{Sm}_{\text {(III) }}$ & $\begin{array}{l}\text { Glycine - Malic acid } \\
\text { Glycine - Maleic acid } \\
\text { Glycine - Malonic acid }\end{array}$ & $\begin{array}{l}9.848 \\
15.530 \\
14.937\end{array}$ & $\begin{array}{l}2.672 \\
-4.465 \\
-3.067\end{array}$ \\
\hline
\end{tabular}

\section{References}

[1] F. A. Cotton and G. Walkinsons, Advanced inorg. Chem, V Edn, Wiley Eastern, New delhi(1968)

[2] A.E. Martell, "Stability constants", Vol. 17 and 25. The chemical society, London (1964 and 1971).

[3] A.E. Martell and R.M. Smith, "Critical Stability Constants" Amino acids,NY (1974).

[4] H. Sigel, "Metal Ions in Biological systems-2", Marcell - Dekker, Ino.,NY (1973).

[5] M.T. Beck, "Chemistry of complex equilibria", Van Nostand, NY, (1970)P. 174.

[6] F. Khan and R. Agrawal, J.Ind. Soc.,Chem., 86, (2009)

[7] P. P.Singh, J.Ind.Chem. Soc.,86,100 (2009)

[8] S. Tabasum, K. S. Siddiqui, N. H. Khan, R, I. Kureshi, and Saazeidi, J.Chem, 26A, 489(1987)

[9] S. Tabasum, K. S. Siddiqui, N. H. Khan, R, I. Kureshi, and Saazeidi, Indian Journal of .Chem,26A,267(1988)

[10] A. Nahendram, K. L. Omprakash, A. V. Chandrapal and M. L. Reddy, Indian Journal of .Chem,27A,267(1988)

[11] H. Irving and H.S. Rossotti, J. Chem. Soc., 76, 2904 (1954)

[12] I. G. Sayee, Talanta, 15,1397(1968).

[13] M.S. Nair and N. Kantan, Ind. J. Chem., 38 A, 1307 (1999) 